\title{
Membranas Híbridas com Potencial Uso em Células a Combustível - Parte 1: Nanocompósitos de Poli(eterimida) Sulfonada
}

\author{
Ana Catarina de Oliveira Gomes, Beatriz Uieda, Andre Akio Tamashiro, \\ Adhemar Collà Ruvolo Filho, Luiz Antonio Pessan \\ Departamento de Engenharia de Materiais - DEMa, Universidade Federal de São Carlos - UFSCar \\ Caio Marcio Paranhos \\ Departamento de Química - DQ, Universidade Federal de São Carlos - UFSCar
}

\begin{abstract}
Resumo: Células a combustível usando membranas poliméricas condutoras de íons representam uma alternativa interessante para substituição de matrizes energéticas convencionais baseadas em combustíveis fósseis e para a geração de energia com mínimo impacto ambiental. Entretanto, as membranas poliméricas atualmente disponíveis apresentam certas propriedades intrínsecas que diminuem a eficiência e a durabilidade sob uso das células construídas, sendo as principais desvantagens o limite de temperatura de uso (devido a necessidade de presença de água para a condução iônica) e suscetibilidade a degradação mecânica, térmica e química. O presente trabalho tem como objetivo a obtenção, caracterização e avaliação do desempenho de membranas poliméricas híbridas baseadas em poli(éter imida) (PEI), um polímero com excelente resistência mecânica e química, e cuja condutividade protônica independe da presença de água, possibilitando o uso a temperaturas mais elevadas. As membranas poliméricas baseadas em poli(éter imida) foram modificadas quimicamente visando o aumento em seu caráter de condutor iônico. A incorporação de um argilomineral com escala nanométrica visou um aumento na resistência mecânica e térmica das membranas obtidas, condições fundamentais para a durabilidade sob uso de células a combustível, além de aumento de propriedades de barreira em relação aos gases de processo. As membranas foram avaliadas por FTIR, DSC, TGA, DMA, densidade, inchamento em água, transmissão de vapor de água e resistência à migração iônica. Os resultados obtidos são promissores, visto que foi possível alterar a propriedade condutora da membrana, sem perdas excessivas na resistência térmica e mecânica.
\end{abstract}

Palavras-chave: Membrana polimérica, nanocompósito polimérico, célula a combustível, eletrólito polimérico.

\section{Hybrids Membranes with Potential Use in Fuel Cells - Part 1: Sulphonated Poly (etherimide) Nanocomposites}

\begin{abstract}
Fuel Cells based in polymeric membranes are an alternative for the conventional energetic matrices based on fossil fuel and generation of energy with minimum environmental impact. However, polymeric membranes available nowadays for this specific use have some disadvantages, like low efficiency and cell durability. The aim of this work was to prepare and to characterize hybrid polymeric membranes for application as hydrogen fuel cell electrolytes. Membranes based in poly(ether imide) were chemically modified with sulfur groups to increase their ionic conductivity. The incorporation of mineral clay in nanometric scale aims to increase their mechanical and thermal properties. The membranes were evaluated by FTIR, DSC, TGA, DMA, density, hot water uptake, water vapor transmission and ionic migration resistance. The results leaded to a better structure versus properties balance, aiming the high performance of the obtained membranes.
\end{abstract}

Keywords: Polymeric membrane, nanocomposite, fuel cell, polymeric electrolyte.

\section{Introdução}

Nos últimos anos, o desenvolvimento de células a combustível tem atraído enorme atenção por parte não somente de grupos de pesquisa, mas também de governos e organizações não-governamentais. Este interesse se deve ao problema crônico e iminente do esgotamento das matrizes energéticas baseadas em combustíveis fósseis. Aliado a este problema, o colossal impacto ambiental sobre todos os ecossistemas terrestres resultante de décadas de utilização não controlada destes combustíveis levou a uma situação alarmante, onde a própria sustentabilidade da qualidade de vida das populações em nível mundial está em cheque. Dentro deste contexto, o governo brasileiro, através do Ministério de Minas e Energia (MME), incluiu o desenvolvimento e utilização de células a combustível baseadas em hidrogênio como uma das metas a serem alcançadas pelo Plano Nacional de Energia 2030 ${ }^{[1]}$.

Células a combustível baseadas em hidrogênio apresentam diversas vantagens quando comparadas às tecnologias convencionais de obtenção energética.

Autor para correspondência: Ana Catarina de Oliveira Gomes, Departamento de Engenharia de Materiais, Universidade Federal de São Carlos - UFSCar, Rodovia Washington Luis, Km 235, Caixa Postal 676, CEP 13565-905, São Carlos, SP, Brasil,

e-mail: acogomes@gmail.com 
As mais expressivas são: a) redução na emissão de poluentes - o principal produto gerado pelas reações químicas no interior da célula é água pura, podendo desta forma classificar as células a hidrogênio como tecnologias com emissão zero; b) elevada eficiência - de uma forma geral, as células a hidrogênio são mais eficientes que as tecnologias baseadas em turbinas ou pistões. Esta característica ganha relevância quando se trata do desenvolvimento de células para pequenas unidades locais geradoras de energia; c) simplicidade - as partes essenciais de uma célula são bastante simples, além de apresentarem poucas partes móveis; baixo nível de ruído - requisito importante para aplicações em áreas hospitalares, equipamentos portáteis, usos militares e residenciais $^{[2,3]}$.

No caso da utilização do hidrogênio como combustível, as células a combustível de membranas condutora de prótons (proton exchange membrane fuel cell - PEMFC) são as mais amplamente utilizadas. A principal vantagem da tecnologia PEMFC é a baixa temperatura de operação, na faixa de $60-140^{\circ} \mathrm{C}$, resultando em um tempo para o início de funcionamento muito mais curto do que o observado para outras tecnologias em células a combustível ${ }^{[2,3]}$

Basicamente, o hidrogênio utilizado como combustível é oxidado no anodo a prótons, liberando elétrons,conforme a Equação 1:

$$
2 \mathrm{H}_{2} \rightarrow 4 \mathrm{H}^{+}+4 \mathrm{e}^{-}
$$

No catodo, oxigênio reage com os elétrons oriundos do circuito elétrico e com os prótons conduzidos pelo eletrólito, resultando em água e liberação de calor (Equação 2):

$$
\mathrm{O}_{2}+4 \mathrm{e}^{-}+4 \mathrm{H}^{+} \rightarrow 2 \mathrm{H}_{2} \mathrm{O}
$$

Para que estas reações ocorram continuamente, evidentemente que os elétrons produzidos no anodo devem migrar através do circuito elétrico para o catodo. Simultaneamente, os íons $\mathrm{H}^{+}$devem ser conduzidos pelo eletrólito. No caso das PEMFC, estes eletrólitos são constituídos pelas membranas poliméricas.

Para serem utilizadas como eletrólitos em PEMFC's membranas poliméricas devem apresentar elevada condutividade a prótons, impermeabilidade aos gases combustíveis e boa estabilidade química e térmica. Atualmente, as membranas poliméricas mais amplamente utilizadas são baseadas em polímeros fluorados, tais como Nafion ${ }^{\circledR}$, Flemion ${ }^{\circ}$, Dow ${ }^{\circledR}$ e Aciplex ${ }^{[4,5]}$.

Tecnicamente, a principal barreira para a utilização maciça das PEMFC nos mais diversos campos de aplicação é a durabilidade sob uso. A principal falha na durabilidade em PEMFC baseadas em polímeros fluorados é a degradação da membrana polimérica. Os principais mecanismos de degradação da membrana são degradação mecânica (alterações dimensionais devido a variações na umidade relativa, baixa umidificação ou a falta de hidratação levam a geração de tensões e falha do material), degradação térmica (devido a variações de temperatura) ou degradação química/ eletroquímica (geração de radicais livres do tipo peróxido e hidroperóxido $)^{[2,3,6]}$.
Dentro do quadro apresentado, o principal desafio atual no desenvolvimento de PEMFC's é a sua utilização a temperaturas elevadas. Sob esta condição de elevada temperatura, as células apresentam aumento na eficiência decorrente do aumento da cinética de oxidação no anodo e consequentemente a utilização de catalisadores e o inconveniente envenenamento por $\mathrm{CO}$ pode ser desconsiderado. Outro importante aspecto da operação das células a temperaturas elevadas é a possibilidade de utilização de biocombustíveis, como o etanol ${ }^{[7,8]}$.

O polímero estudado neste trabalho foi a poliéterimida (PEI), um termoplástico amorfo com temperatura de transição vítrea de $\sim 215^{\circ} \mathrm{C}$ e com excelente resistência mecânica e química. Como requisitos básicos para que um polímero seja um bom condutor iônico, as seguintes características estruturais devem estar presentes: a) presença de sítios com cargas fixas; b) presença elevada de volumes livres. Ao contrário das membranas fluoradas, a condutividade protônica em PEI é independente da presença de água (carreador de íons). No caso da PEI, este carreamento é realizado a partir de domínios iônicos presentes na cadeia polimérica. Entretanto, a condutividade protônica pode ser alterada pela inserção de sítios contendo cargas fixas, que temporariamente podem receber ou liberar íons em movimento. Esta inserção pode ser alcançada através da sulfonação das cadeias de PEI. A presença de volumes livres aumenta a capacidade difusional dos íons ao longo da matriz polimérica. Portanto, a sulfonação da PEI melhora a condutividade protônica da membrana ao alterar simultaneamente o número de sítios portadores de cargas e a distribuição local dos volumes livres em decorrência do elevado volume molecular dos grupos sulfonados.

Polímeros sulfonados têm sido pesquisados para os mais diversos fins, geralmente relacionada à separação seletiva de espécies iônicas ou polares, sendo mais recente o estudo em aplicações como membranas condutoras de íons em baterias e células a combustível ${ }^{[9]}$.

A modificação de PEI por sulfonação é relatada na literatura principalmente a partir de três agentes: ácido sulfúrico concentrado, ácido clorosulfônico e sulfato de acetila ${ }^{[9-11]}$. Dentre elas, o sulfato de acetila é o mais promissor devido à simplicidade da obtenção do reagente e menor possibilidade de degradação da cadeia principal do polímero ${ }^{[10]}$

Para aumentar a resistência mecânica e térmica da membranas, nanopartículas de argilominerais foram incorporadas na matriz polimérica. O intuito é a avaliação da presença da nanopartícula sobre as propriedades térmicas e mecânicas da membrana, juntamente com as possíveis alterações na condutividade protônica do sistema. Uma vez que argilominerais possuem moléculas de água que constituem a estrutura cristalina, é interessante avaliar como a presença da argila pode influenciar a condutividade protônica global da membrana e qual o possível mecanismo desenvolvido.

Nanocompósitos de polímeros sulfonados têm sido estudados para fins de uso em células a combustível, sendo mais comum o uso de sílica, zeólitas, titânio e nanotubos de carbono ${ }^{[12]}$. O uso de nanoargilas é bastante recente neste campo e é necessário estudos mais aprofundados 
sobre o efeito da incorporação dessas nanopartículas visando aplicações em células a combustível ${ }^{[13]}$. De forma geral, a incorporação de nanoargilas parece aumentar estabilidade térmica e mecânica, além de criar barreiras para a difusão das espécies combustível permitindo níveis razoáveis de condutividade protônica ${ }^{[14]}$. O polímero mais comumente estudado é a poli(éter éter cetona) sulfonada, não sendo encontrados trabalhos sobre o uso de PEI sulfonada com a incorporação de nanopartículas.

As membranas poliméricas obtidas devem apresentar propriedades mecânicas e térmicas superiores às das membranas fluoradas comerciais disponíveis para a construção de PEMFC's. Além disso, a condutividade protônica das membranas baseadas em PEI deve ser superior e independente da presença de água, permitindo a sua utilização a elevadas temperaturas.

\section{Experimental}

\section{Materiais}

Poli(éter imida) (Ultrem 1010, $53000 \mathrm{~g} / \mathrm{mol}$ ) foi doada por Sabic Corporation. Dimetildiclorosilano foi adquirido da Sigma-Aldrich Inc. A argila natural sepiolita foi adquirida da Flucka Inc. N-metil-pirrolidona, ácido sulfúrico, anidrido acético, álcool etílico, tolueno, diclorometano, cloreto férrico, peróxido de hidrogênio, tetracloreto de carbono e cloreto de sódio foram adquiridos da Vetec Química S.A. Todos os reagentes tem grau de pureza P.A. e foram utilizados como recebidos.

\section{Sulfonação da matriz polimérica}

$\mathrm{O}$ agente sulfonante foi preparado a partir de N-metilpirrolidona (NMP), anidrido acético e ácido sulfúrico, na razão de 20:2:1 (em volume), para a formação do reagente "sulfato de acetila"[9]. O procedimento consistiu em dissolver aproximadamente $6 \mathrm{~g}$ de polímero em $35 \mathrm{~mL}$ de NMP, a $80^{\circ} \mathrm{C}$ em banho de óleo de silicone, sob agitação constante. Em seguida, por meio de um funil de adição graduado com equalizador de pressão, adicionou-se $10 \mathrm{~mL}$ de agente sulfonante por gotejamento lento ao longo de uma hora. Após isso, deixou-se a reação ocorrer por mais uma hora. A reação foi terminada com a adição de álcool etílico ao meio reacional, então o produto foi precipitado por gotejamento lento em álcool etílico.

$\mathrm{O}$ produto foi filtrado em funil de Buchner, seco em estufa sob vácuo a temperatura ambiente por 48 horas e, em seguida, em uma estufa com circulação de ar forçado a $50^{\circ} \mathrm{C}$ por aproximadamente 6 horas.

\section{Modificação da sepiolita}

A modificação da superfície da sepiolita foi realizada com o agente de modificação dimetildiclorosilano ${ }^{[15]}$. A sepiolita foi submetida a refluxo de solvente por aproximadamente 6 horas em um aparelho soxhlet, com $30 \%$ em volume de dimetildiclorosilano em tolueno. A mistura foi resfriada, filtrada e lavada com clorofórmio e metanol, e seca em estufa sob vácuo a $120{ }^{\circ} \mathrm{C}$ por 24 horas.

\section{Preparação das membranas por "casting"}

A um frasco de vidro schott adicionou-se diclorometano e polímeros, obtendo-se uma solução
$10 \%$ massa/volume. O sistema foi mantido sob agitação até que o polímero solubilizasse. A formulação testada consiste em uma blenda na proporção $75 / 25$ de polímero sulfonado e polímero não modificado.

Os filmes foram preparados por vazamento com auxílio da ferramenta "Doctor Blade", para controle de espessura. O filme foi formado em dessecador com atmosfera previamente saturada com solvente, por aproximadamente $45 \mathrm{~min}$. Os filmes foram secos em uma estufa com circulação de ar forçado a $80{ }^{\circ} \mathrm{C}$ por 15 horas.

\section{Incorporação de argilomineral na matriz polimérica}

A incorporação se iniciou com uma solução contendo argila e solvente tratadas em ultrassom por aproximadamente 1 hora, para a dispersão da argila (modificada ou não) e, em seguida, o polímero foi adicionado. A solução foi mantida sob agitação magnética vigorosa por aproximadamente 24 horas. Os filmes foram preparados da maneira descrita no item acima.

\section{Estudo espectrofotométrico por infravermelho (IR)}

A análise foi realizada com amostras na forma de filmes, por meio de equipamento Nicolet 6700 da Thermo Cientific, em um intervalo de 4000 a $400 \mathrm{~cm}^{-1}$, em modo de transmissão. Os resultados, em absorbância, foram normalizados em função da espessura das amostras, medidas em micrômetro digital Mitutoyo 0-25 mm, de $0,001 \mathrm{~mm}$ de precisão.

\section{Análise elementar}

O experimento foi realizado com amostras do polímero sulfonado na forma de flocos em um equipamento Eager 200 da CE Intruments. O teor de ácido sulfônico, ou seja, o grau de sulfonação (DS) dos polímeros, foi determinado com precisão através de análise elementar. A relação utilizada para o calculo foi a seguinte: (Equação 3)

$$
D S=\frac{M M p o l \times 100 \cdot S}{32 \times 100-80 \cdot S}
$$

onde $\mathrm{S}$ é o teor de enxofre (porcentagem em massa) no polímero, MM pol é a massa molar da unidade monomérica do polímero e os números 32 e 80 são os pesos moleculares do enxofre e do grupo sulfônico, respectivamente ${ }^{[7]}$.

\section{Calorimetria Diferencial de Varredura (DSC)}

As curvas de DSC foram obtidas por meio de um equipamento Q2000 da TA Instruments, com amostras de polímero na forma de flocos e de filmes. Utilizaramse cadinho de alumínio e atmosfera de nitrogênio. O intervalo de temperatura da análise foi de 30 a $250^{\circ} \mathrm{C}$ e a taxa de aquecimento utilizada foi de $10^{\circ} \mathrm{C}$ por minuto.

\section{Análise Termogravimétrica (TGA)}

As curvas de TGA foram obtidas por meio de um equipamento Q50 da TA Instruments. Utilizaram-se amostras na forma de flocos e de filmes, atmosfera de nitrogênio e cadinho de platina. A taxa de aquecimento foi de $20^{\circ} \mathrm{C}$ por minuto e a temperatura final do ensaio foi $800^{\circ} \mathrm{C}$. 


\section{Análise Dinâmico-Mecânica (DMA)}

As curvas de DMA foram obtidas por meio do equipamento Q800 da TA Instruments, com amostras de polímero na forma de filmes de geometria retangular de dimensões aproximadas de $15 \mathrm{~mm}$ x 6,5 mm e espessura entre 0,02 e $0,04 \mathrm{~mm}$. A amostra foi submetida a uma rampa de temperatura a uma taxa de $3^{\circ} \mathrm{C} / \mathrm{min}$, com freqüência de deformação de $1 \mathrm{~Hz}$.

\section{Inchamento em água}

O teste de inchamento das membranas em água foi realizado com amostras na forma de filmes de dimensões aproximadas $2 \mathrm{x} 2 \mathrm{~cm}$. As membranas foram pesadas e acondicionadas em água deionizada, em um banho Haake DC 30 a $80^{\circ} \mathrm{C}$, durante aproximadamente 40 horas. Nas primeiras 4 horas as amostras foram pesadas a cada 30 minutos. Os resultados obtidos foram ajustados à função de Boltzmann (curva sigmoidal - Equação 4) para melhor visualização do comportamento de inchamento da amostra.

$$
y=\frac{A_{1}-A_{2}}{1+e^{\left(x-x_{0}\right) / d x}}+A_{2}
$$

\section{Resistência química}

A avaliação da resistência química das membranas foi realizada por meio de Reagente de Fenton (1 ppm de cloreto férrico em peróxido de hidrogênio 20 volumes). Em copos de vidro colocaram-se as amostras das membranas de polímero puro e sulfonado acondicionadas em Reagente de Fenton. Deixou-se o sistema em repouso por uma semana.

\section{Permeação a vapor de água}

Este ensaio foi realizado em copos de vidro segundo a Norma ASTM E96, montados como representado na Figura 1, com atmosfera controlada em umidade relativa de $16 \%$ e temperatura de $23{ }^{\circ} \mathrm{C}$, ao longo de 5 dias. A amostra foi fixada nos copos de vidro parcialmente preenchidos com água deionizada por meio de cola epóxi, impermeável ao vapor de água. O peso inicial do sistema foi determinado em balança analítica de precisão, e a mudança de peso ao longo do tempo monitorada por pesagens periódicas. A relação entre a área de membrana exposta ao vapor de água, a espessura da membrana e a perda de massa de vapor de água ao longo do tempo foi então utilizada para o calculo de permeação.

\section{Resistência à migração iônica}

Este ensaio foi realizado com o auxílio de um sistema montado no Laboratório de Polímeros do Departamento de Química, como o apresentado na Figura 2. Os filmes foram posicionados no meio de uma célula de duas câmaras e, em seguida, esta célula foi preenchida com solução aquosa de $\mathrm{NaCl} 3,5 \%$. Os valores de corrente foram medidos através de eletrodos de platina enquanto variava-se a tensão elétrica aplicada, na faixa de 0,5 a $2,5 \mathrm{~V}$.

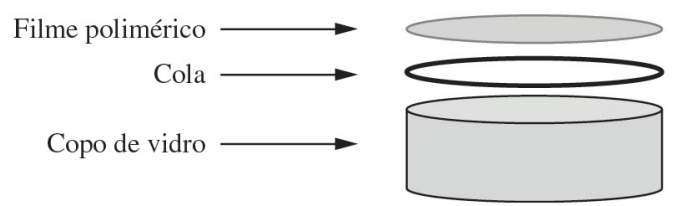

Figura 1. Esquema de permeação a vapor de água.

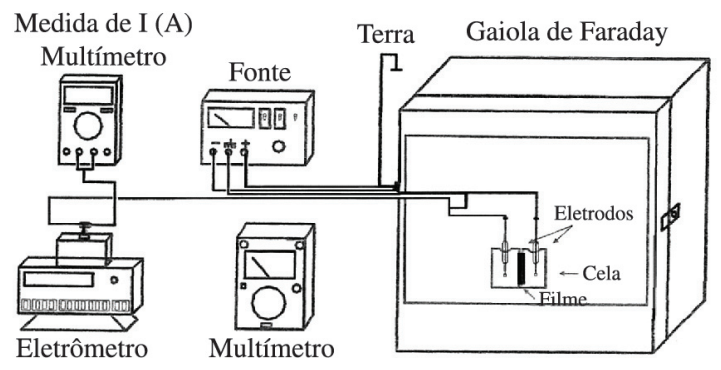

Figura 2. Esquema da aparelhagem de resistência à migração iônica.

A cada medida foi realizada esta varredura, e a inclinação da reta obtida pelo gráfico de tensão elétrica versus corrente forneceu o valor da resistência para cada ponto. $\mathrm{O}$ ensaio foi conduzido até que o valor da resistência se tornasse constante.

\section{Resultados e Discussões}

\section{Sulfonação da Poli(éter imida)}

A sulfonação é uma rota apropriada para modificação de polímeros com anéis aromáticos em sua cadeia principal. Como a sulfonação é uma reação eletrofílica, sua realização dependerá dos tipos de grupos ligados ao anel aromático ${ }^{[8]}$, dependendo portanto da estrutura química do polímero a ser modificado. Esta reação, porém pode ser complexa devido sua reversibilidade e possibilidade de degradação do polímero $^{[8]}$. Trabalhos anteriores indicaram grande degradação para tentativas de sulfonação a partir de $20 \%{ }^{[16]}$. Assim, no caso da PEI, é preciso manter um baixo grau de sulfonação para melhor controle da reação, evitar a degradação do polímero e o aumeno excessivo da solubilidade em água. Por este motivo, optou-se por manter a sulfonação na faixa de $10 \%$ a $20 \%$, na qual ainda não se relata na literatura tais efeitos deletérios.

A análise elementar da amostra de PEI sulfonada forneceu o valor de $0,99 \%$ em massa de enxofre. Utilizando a equação 3, descrita anteriormente, foi obtido o valor de $18,97 \%$ de grau de sulfonação.

A Figura 3 mostra o espectro obtido pela análise de infravermelho para a amostra de filme de PEI pura e após a sulfonação. As diferenças entre os espectros indicam o sucesso da sulfonação. De acordo com a literatura, existem três absorbâncias típicas para os grupos sulfônicos $(\mathrm{S}=\mathrm{O})$ em aproximadamente 1680,1170 e $780 \mathrm{~cm}^{-1[9]}$. No espectro apresentado, apenas a banda em $1687 \mathrm{~cm}^{-1}$ pode ser identificada, devido ao baixo teor de sulfonação. Esta banda representa a interação do grupo sulfônico no anel aromático da PEI com a carbonila da imida-heterocíclica. Essa banda característica do grupo sulfona não aparece 
no espectro da PEI não modificada, e é menos intensa no espectro da blenda.

\section{Modificação da sepiolita}

A Figura 4 apresenta os espectros de FTIR da sepiolita pura e da modificada. A presença da modificação com adsorção do grupo silano é confirmada pela presença da banda a $2964 \mathrm{~cm}^{-1}$, relativa ao estiramento da ligação C-H e pela intensa banda a $800 \mathrm{~cm}^{-1}$, relativa ao estiramento da ligação $\mathrm{C}-\mathrm{Cl}^{[15]}$.

As curvas de Difração de raios-X (Figura 5) mostram que a sepiolita apresenta uma intensa reflexão localizada a $2 \theta=7,2^{\circ}(\mathrm{d}=12,8 \AA$ ). Esta reflexão é associada ao espaçamento dos planos cristalinos formadores dos poros zeolíticos da sepiolita $^{[15]}$, Não existe dferença significativa entre os padrões de difração de raios-x da sepiolita natural e modificada, indicando que a modificação química ocorreu apenas na superfície da argila.

\section{Incorporação de sepiolita em blendas de PEI/PEIS 25/75}

Trabalhos anteriores ${ }^{[16]}$ mostraram que a PEIS pura é muito quebradiça, o que inviabiliza a formação de filmes por "casting" capazes de serem manipulados propriamente. Para reduzir este problema, optou-se

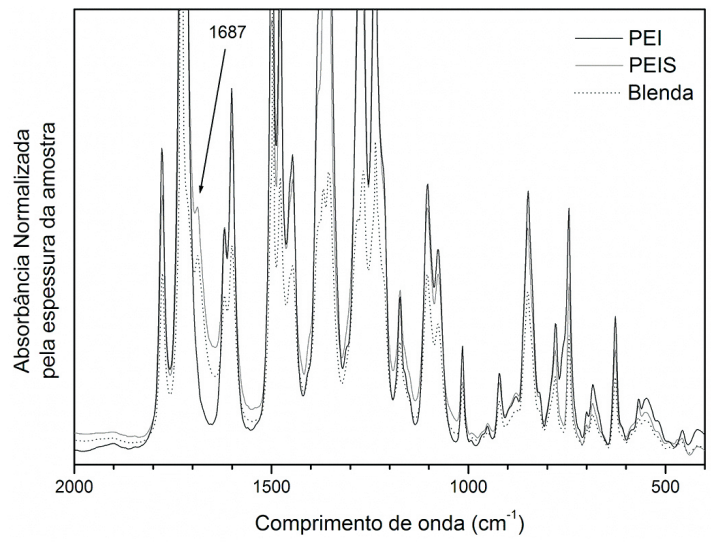

Figura 3. Comparação de FTIR para as amostras PC puro, PCS e a blenda.

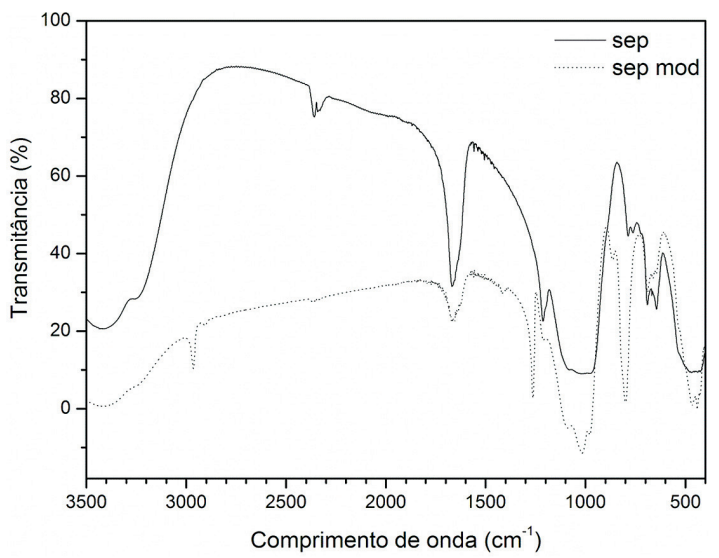

Figura 4. Comparação de FTIR das amostras de sepiolita natural e silanizada. por adicionar um pequeno teor (o mínimo possível) de PEI não modificada ao nanocompósito de modo que seja possível a manipulação das amostras sem grande alteração da capacidade de migração protônica. O teor definido neste trabalho ${ }^{[16]}$ foi de $25 \%$ de PEI virgem.

A incorporação da sepiolita modificada nas membranas de blenda PEI/PEIS resulta no surgimento da reflexão a $2 \theta=7,1^{\circ}$ (Figura 6), confirmando a presença da argila. Nota-se que a intensidade associada a esta reflexão aumenta com o aumento no teor de sepiolita, assim como a presença de modificação na superfície da sepiolita leva a uma diminuição da intensidade e aumento de largura dos picos, fenômeno associado a melhor dispersão da argila na matriz.

$\mathrm{Na}$ Figura 7 são apresentados os espectros de absorbância de radiação infravermelha obtidos para blendas com adição de sepiolita ou sepiolita modificada em proporções de $1,5 \%$ e 3,0\% em massa.

Não é possível notar diferenças significativas entre os espectros, exceto talvez o desaparecimento do desdobramento de algumas bandas (como 1367 e $1353 \mathrm{~cm}^{-1}$, por exemplo), que pode ser relacionado à interação da argila com a matriz polimérica. $\mathrm{O}$ desaparecimento de desdobramento ocorre mais intensamente para amostras com argila modificada.

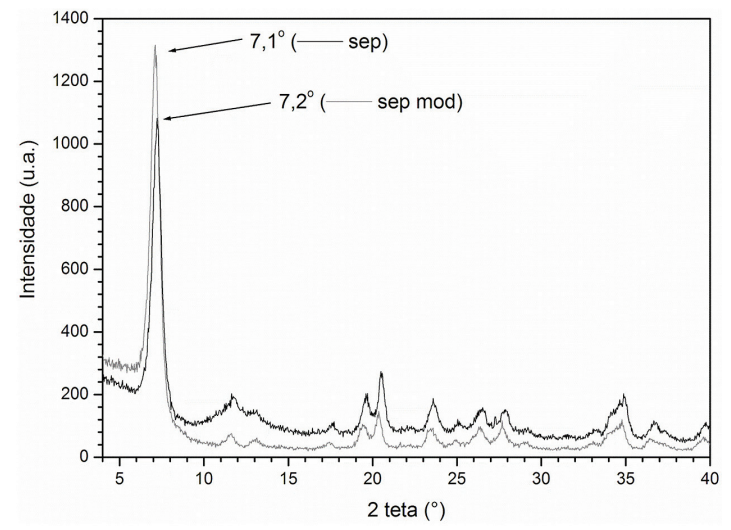

Figura 5. DRX para as amostras de sepiolita natural e silanizada,

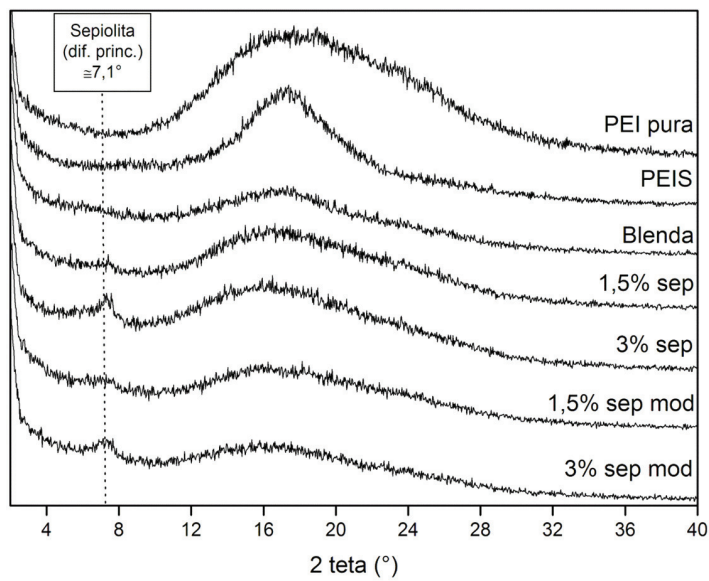

Figura 6. DRX para todas as amostras em filme. 
Na Tabela 1, temos os dados da análise termogravimétrica das blendas com e sem adição de sepiolita, modificada ou não. Os valores mostram que, com o aquecimento, ocorre a eliminação dos grupos sulfona em torno de $200^{\circ} \mathrm{C}$, levando a uma perda em massa de 10 a $12 \%$. Próximo a $540{ }^{\circ} \mathrm{C}$ temos a taxa máxima de degradação, onde ocorre a quebra das cadeias principais de poli(éter imida) ${ }^{[17]}$.

Uma primeira avaliação da mobilidade das cadeias do polímero sulfonado foi realizada pela determinação da temperatura de transição vítrea (Tg). Pela análise das curvas do segundo ciclo de aquecimento para as amostras de PEI pura e PEI sulfonada (Tabela 2), pode-se observar que houve uma diminuição da $\mathrm{Tg}$, de aproximadamente $65^{\circ} \mathrm{C}$ para a PEI sulfonada, em relação a PEI pura. Esse resultado é uma indicação da modificação molecular devido a sulfonação do polímero ${ }^{[10]}$.

Os dados obtidos do DSC para as misturas PEI/ PEIS (25/75) pura e com adição de sepiolita e sepiolita

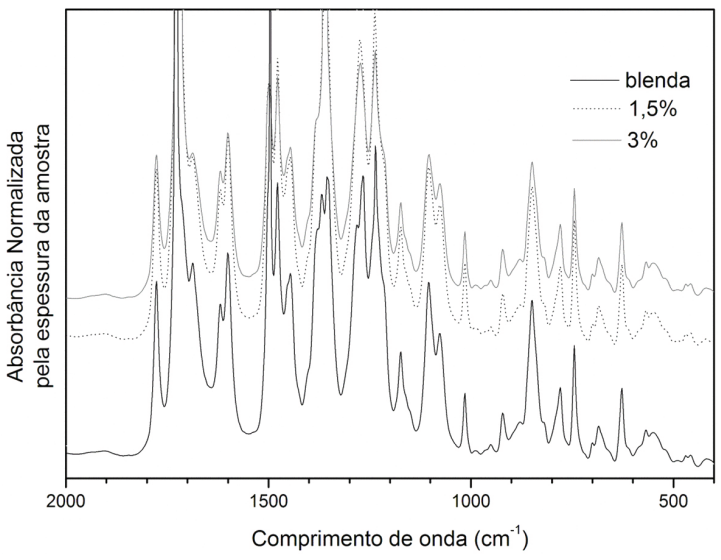

(a) modificada são apresentados na Tabela 2. Nota-se que não houve mudança significativa com a adição de sepiolita não modificada na mistura PEI/PEIS. Já o acréscimo de sepiolita modificada resultou em um aumento na temperatura de transição das amostras, entre 10 e $20{ }^{\circ} \mathrm{C}$, indicando, neste caso, melhor interação da sepiolita modificada com a matriz polimérica (PEI não modificada), resultando em uma menor mobilidade molecular, e consequentemente, maior $\mathrm{T}_{\mathrm{g}}$. Este é um indício de que, provavelmente, a sepiolita modificada (onde a polaridade é reduzida em relação à sepiolita natural) está preferencialmente na fase PEI pura, que resulta em menor mobilidade molecular e aumento da Tg.

Complementando a avaliação por DSC, a Figura 8 apresenta os resultados de DMA. Nas curvas da Figura 8a, podemos observar que a blenda apresenta duas transições secundárias, sendo uma relativa à porção de PEI pura e a de menor temperatura, para a fração PEIS.

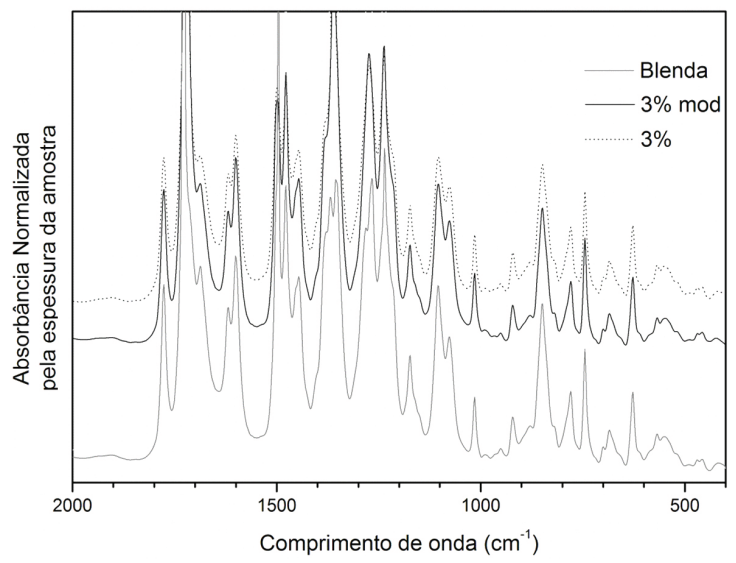

(b)

Figura 7. FTIR de amostras (a) com adição de sepiolita não modificada e (b) comparação entre os mesmos teores de argila modificada e não modificada.

Tabela 1. Análise térmica das amostras de PEI e PEI sulfonado, e suas blendas.

\begin{tabular}{|c|c|c|c|c|c|}
\hline & \multicolumn{4}{|c|}{ TGA } & \multirow{2}{*}{$\frac{\text { DSC }}{\operatorname{Tg}\left({ }^{\circ} \mathrm{C}\right)}$} \\
\hline & $1^{\mathrm{a}} \operatorname{deg}\left(\right.$ on set $\left.-{ }^{\circ} \mathrm{C}\right)$ & Perda de massa $(\%)$ & $\operatorname{Tg}\left({ }^{\circ} \mathrm{C}\right)$ & Resíduo (\%) & \\
\hline PEI & - & - & 532 & 54 & 220 \\
\hline PEIS & 160 & 10 & 533 & 44 & 155 \\
\hline PEI/PEIS & 242 & 12 & 524 & 47 & 140 \\
\hline PEI/PEIS 1,5 sep & 228 & 10 & 525 & 41 & 137 \\
\hline PEI/PEIS 3 sep & 232 & 11 & 531 & 43 & 143 \\
\hline PEI/PEIS 1,5 sepmod & 155 & 11 & 529 & 44 & 160 \\
\hline PEI/PEIS 3 sepmod & 231 & 11 & 531 & 46 & 152 \\
\hline
\end{tabular}

Tabela 2. Propriedades físico-químicas das blendas.

\begin{tabular}{lccr}
\hline & & \multicolumn{1}{c}{ Inchamento } \\
\cline { 2 - 4 } & Máximo de inchamento real (\%) & Máximo de inchamento modelado (\%) & Perda de massa (\%) \\
\hline PEI/PEIS & $28 \pm 1$ & $22 \pm 6$ & $5 \pm 1$ \\
PEI/PEIS sep 1,5\% & $29 \pm 5$ & $23 \pm 7$ & $10 \pm 5$ \\
PEI/PEIS sep 3\% & $17 \pm 4$ & $17 \pm 4$ & $4 \pm 4$ \\
PEI/PEIS sep mod 1,5\% & $26 \pm 3$ & $26 \pm 9$ & $13 \pm 3$ \\
PEI/PEIS sep $\bmod 3 \%$ & $20 \pm 2$ & $18 \pm 3$ & $7 \pm 2$ \\
\hline
\end{tabular}




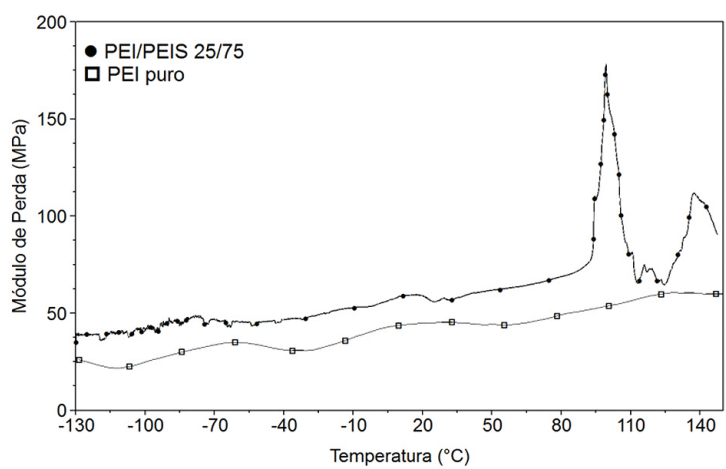

(a)

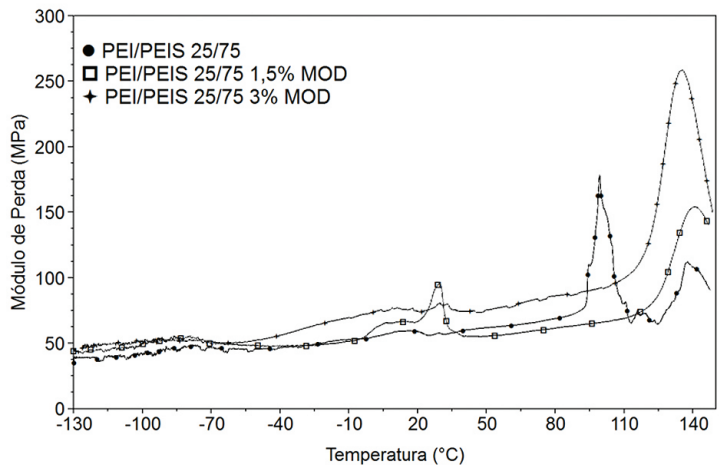

(c)

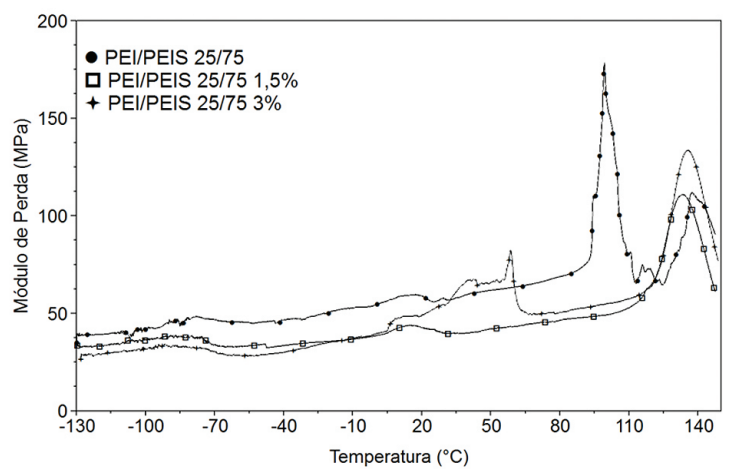

(b)

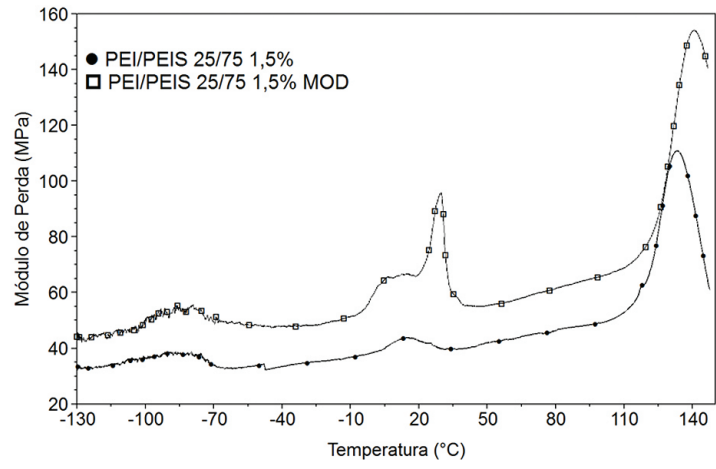

(d)

Figura 8. Curvas de módulo de perda das amostras (a) PEI pura e blenda (b) nanocompósitos com argila não modificada, (c) nanocompósitos com argila modificada e (d) comparação entre amostra com argila mofidicada e natural.

A presença de duas transições sugere a separação de fases entre a PEI não modificada e a sulfonada, conforme já descrito na literatura ${ }^{[7]}$, o que corrobora a discussão de tendência de segregação da argila modificada para a fase de PEI não modificada.

Polimidas normalmente apresentam transições abaixo da $\mathrm{Tg}$ correspondentes a à pequenos movimentos de pequenas unidades em sua estrutura molecular. Processos de movimentação a baixas temperaturas em polímeros aromáticos rígidos tem sido relatado como diversos mecanismos, entre eles rotação de grupos metil, "flip" ou giro de grupos fenila ou de toda a cadeia principal, entre outros. Esses processos também podem ser considerados uma superposição de movimentos intracadeia e movimentos cooperativos a alta temperatura, sendo influenciados por umidade, história térmica e morfologia ${ }^{[18]}$.

A primeira transição ocorre na faixa de -100 a $-50{ }^{\circ} \mathrm{C}$ e pode ser relacionada ao movimento de giro dos anéis aromáticos. A segunda transição, em aproximadamente $20^{\circ} \mathrm{C}$ está relacionada ào mesmo movimento de giro, porém de outra unidade química da cadeia polimérica da PEI. E em aproximadamente $100^{\circ} \mathrm{C}$ temos uma transição que acreditamos estar relacionada à movimentos cooperativos de cadeia. As transições secundárias da PEI também ocorrem para a blenda, sendo que o movimento cooperativo $\left(\cong 100^{\circ} \mathrm{C}\right)$ é muito mais significativa que para a PEI pura.

As Figuras 8 b e c apresentam as curvas de módulo de perda para as amostras de blendas com sepiolita incorporada. Podemos observar que a incorporação de sepiolita natural desloca a transição relacionada à PEIS para temperaturas mais baixas, ou seja, a presença da argila não modificada aumenta a mobilidade molecular das cadeias modificadas quimicamente.

O aumento do teor de argila causa a formação de populações de diferentes mobilidades moleculares, dando ao pico de transição um aspecto "trimodal".

Conforme observado na Figura 8d, a incorporação da argila modificada faz com que este deslocamento seja ainda maior, sugerindo maior interação da argila com as cadeias da matriz como um todo.

\section{Inchamento em água}

Na Figura 9 é possível observar que houve inchamento em água para todas as amostras, sendo menor para os maiores teores de sepiolita, independente de ser modificada ou não.

Os desvios observados para os valores medidos para geração das curvas estão relacionados a baixa massa dos filmes utilizados nos testes de inchamento e aos erros de pesagem relacionados a este fato. A presença de sepiolita parece estar ajudando a manter a estrutura do filme sem a entrada de moléculas de água. Ao longo do ensaio, entretanto, as amostras se apresentaram cada vez mais quebradiças, indicando diminuição da resistência à degradação por hidrólise ${ }^{[10]}$.

Após a secagem foi possível notar que houve a solubilização parcial do polímero em água, com redução em relação à massa inicial de até $13 \%$ (Tabela 2). O 
aumento de solubilidade em água com a sulfonação do polímero é relatado na literatura ${ }^{[19]}$. O grau de solubilização foi maior para as amostras com 1,5\% de sepiolita, modificada ou não. Ao que parece, os maiores teores de sepiolita evitam, em parte, a solubilização do polímero sulfonado. Este efeito está de acordo com a resistência ao inchamento.

É possível que a argila esteja agindo como um "reticulante físico", diminuindo a solubilidade do polímero sulfonado. Este efeito é relatado na literatura para outros compostos inorgânicos com a presença de cargas superficiais ${ }^{[13,20]}$.

Relembrando a composição da amostra, a matriz é uma mistura 25/75 de PEI não modificada e PEI sulfonada, com cerca de $10 \%$ de sulfonação. Ou seja, na blenda como um todo, a porcentagem de modificação é cerca de $8 \%$, logo a matriz é formada pela grande maioria de cadeias de PEI não modificada. A argila não modificada tem caráter polar e provavelmente interage com a fase segregada de PEI modificada (mais polar), segregação esta indicada pelo DMA. A PEI é modificada por grupos sulfona, que são, por natureza, grandes em volume e apresentam cargas permanentes. Espera-se que a interação com a argila não seja mais significativa que a modificação química da PEI, e, conforme esperado, sua incorporação realmente não causa modificações significativas na $\mathrm{T}_{\mathrm{g}}$, conforme apresentado nas análises de DSC.
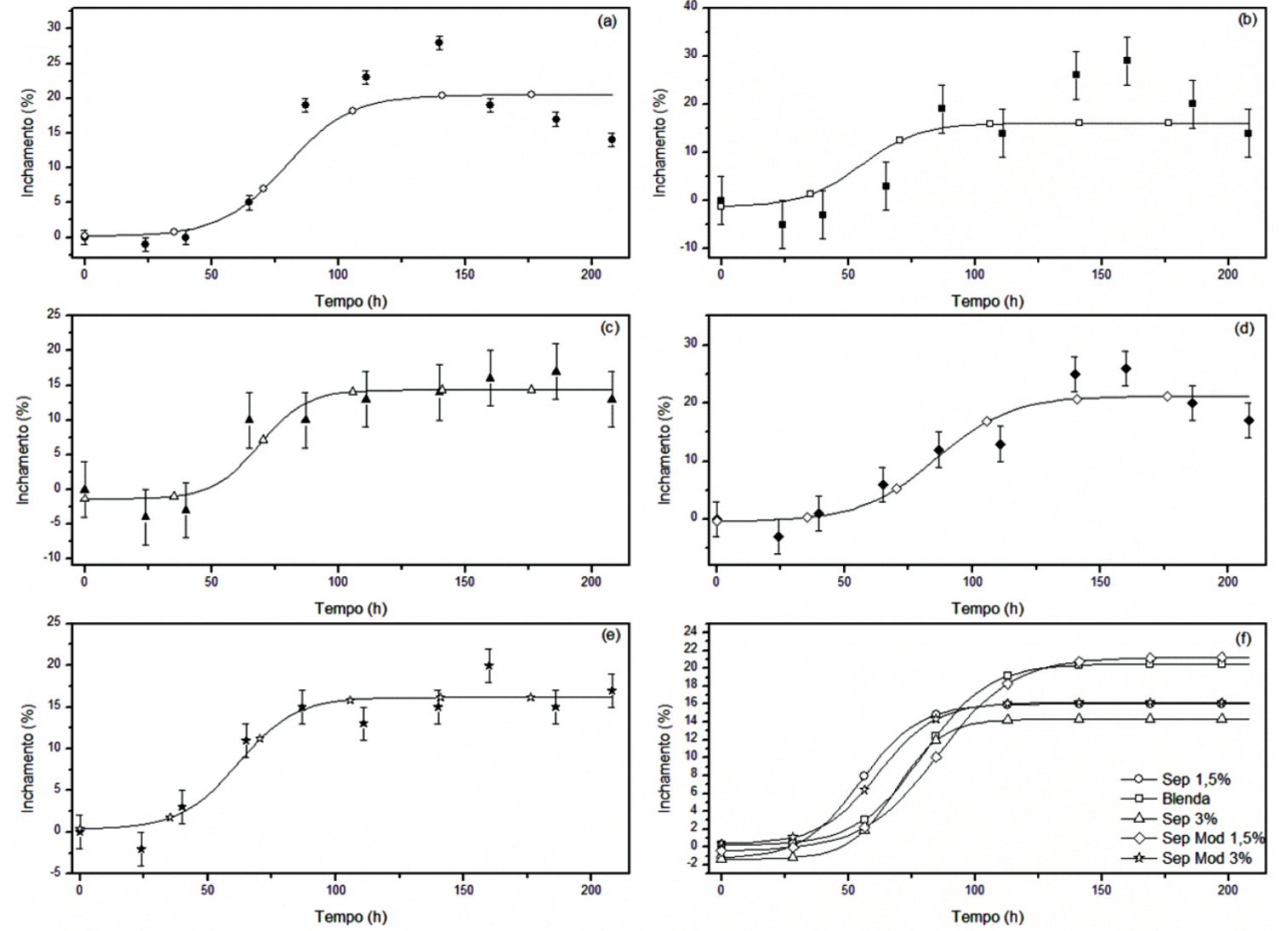

Figura 9. Inchamento das amostras em água a $80^{\circ} \mathrm{C}$, sendo (a) PEI/PEIS, (b) PEI/PEIS sep 1,5\%, (c) PEI/PEIS sep 3\%, (d) PEI/PEIS sep mod 1,5\%, (e) PEI/PEIS sep mod 3\% e (f) apenas as curvas de ajuste para função de Boltzman para todas as amostras, para melhor comparação. 
Tabela 3. Transmissão de vapor de água e Permeação.

\begin{tabular}{|c|c|c|c|c|c|}
\hline & PEI/PEIS (25/75) & SEP 1,5\% & SEP 3,0\% & SEP MOD 1,5\% & SEP MOD 3,0\% \\
\hline WVT $\left[\mathrm{g} /\left(\right.\right.$ dia.m $\left.\left.{ }^{2}\right)\right]$ & $169 \pm 47$ & $326 \pm 121$ & $323 \pm 51$ & $179 \pm 66$ & $158 \pm 27$ \\
\hline $\mathrm{P}\left[10^{-9} \mathrm{~g} /(\right.$ Pa.s.m) $)$ & $3,1 \pm 1$ & $8,5 \pm 1,7$ & $7,8 \pm 0,9$ & $2,2 \pm 0,5$ & $2,6 \pm 0,6$ \\
\hline
\end{tabular}

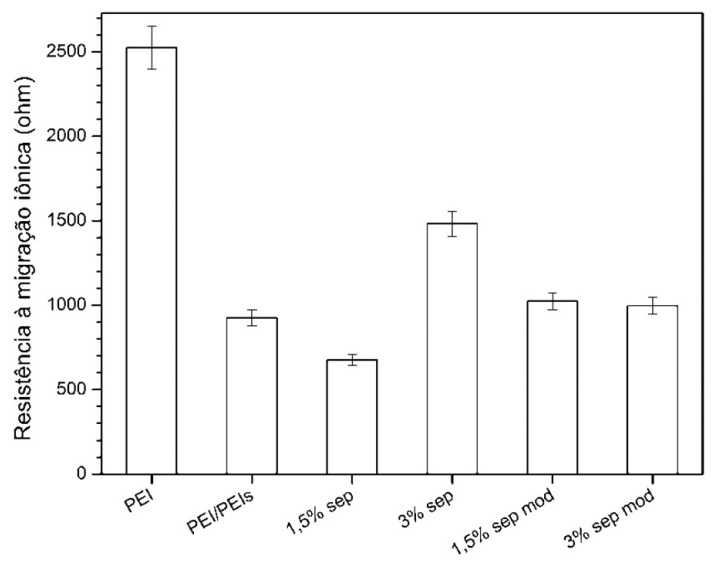

Figura 10. Resistência a migração iônica para todas as amostras testadas.

sepiolita modificada em proporção de $1,5 \%$ e $3,0 \%$ em massa. Comparando-se os valores de WVT e de P da mistura PEI/PEIS com sepiolita modificada, observou-se que o fluxo de vapor de água foi menor que o da PEI com sepiolita não modificada, sendo obtidos valores próximos ao da mistura PEI/PEIS, sem a presença de sepiolita, comprovando a melhor interação da sepiolita com a matriz polimérica quando modificada. Esta menor permeação também é interessante para as aplicações em células a combustível.

\section{Resistência à migração iônica}

A Figura 10 apresenta os valores de resistência a migração iônica. Os valores medidos nos levam a concluir que a presença de grupos sulfona na cadeia principal aumenta consideravelmente a migração iônica através do filme polmérico, sendo que essa migração aumenta com o aumento do teor de sepiolita incorporada. No caso da sepiolita modificada, devido à maior interação de sua superfície com a matriz, a incorporação da argila aumenta a migração, e esta não varia significativamente com a variação do teor de argila. É possível que este efeito se deva à estrutura da sepiolita. Sua forma acicular com a presença de íons na superfície permite a formação de caminhos preferenciais, semelhante a um processo de percolação, para a transmissão de espécies iônicas, em combinação com os grupamentos sulfona. A estrutura inorgânica leva a um comportamento de melhor barreira para vapor de água, a presença de íons permite que isso ocorra sem alterar significativamente a resistência iônica. Este comportamente é altamente desejável para aplicações em células a combustível.

\section{Conclusões}

A sulfonação da PEI se mostrou muito promissora para o uso do material em células a combustível. Apesar de a modificação química ter levado à diminuição da estabilidade térmica e aumento da solubilidade e inchamento da membrana, a incorporação da sepiolita minimizou esses problemas. Assim, o sistema estudado é adequado para a obtenção de um balanço equilibrado de propriedades desejáveis a uma membrana polimérica com aplicações como meio eletrólito.

\section{Agradecimentos}

Os autores agradecem às agências de fomento CAPES, CNPq e FAPESP pelo auxílio financeiro, e à SABIC pela doação da PEI.

\section{Referências Bibliográficas}

1. Brasil. Ministério de Minas e Energia. - "Plano Nacional de Energia 2030" (2009). Disponível em: <http://www.mme. gov.br/mme/galerias/arquivos/publicacoes/pne_2030/ PlanoNacionalDeEnergia2030.pdf $>$. Acesso em: 04 ago. 2009

2. Larminie, J. \& Dicks, A. - "Fuel cell systems explained", 2nd ed., John Wiley, Chichester (2003). http:// dx.doi.org/10.1002/9781118878330

3. O'Hare, R. P.; Cha, S. W.; Colella, W. \& Prinz, F. B. - "Fuel cells Fundamentals", John Wiley, New York (2006).

4. Perles, C. E. - Polímeros, 18, p.281 (2008).

5. Savagodo, O. J. - Power Sourc., 127, p.135 (2004).

6. Wua, J.; Yuana, X. Z.; Martina, J. J.; Wanga, H.; Zhanga, J.; Shena, J.; Wua, S. \& Meridaa, W. J. - Power Sourc., 184, p.104 (2008).

7. Shu, Y. C.; Chuang, F. S.; Tsen, W. C.; Chow, J. D.; Gong, C. \& Wen, S. - J. Appl. Polym. Sci., 107, p.2963 (2008). http://dx.doi.org/10.1002/app.27481

8. Loredo, D. E. S., Paredes, M. L. L. \& Sena, M. E. - Mat. Let., 62, p.3319 (2008). http://dx.doi.org/10.1016/j. matlet.2008.02.040

9. Genies, C.; Mercier, R.; Sillion, B.; Cornet, N.; Gebel, G. \& Pineri, M. - Polymer, 42, p.359 (2001). http://dx.doi. org/10.1016/S0032-3861(00)00384-0

10. Pinto, B. P.; Santa Maria, L. C. \& Sena, M. E. - Mater. Let., 61, p.2540 (2007). http://dx.doi.org/10.1016/j. matlet.2006.09.060

11. Pillai, R. T.; Lakshmi, S. M.; Bhattacharya, S. \& Varma, I. K. - High Perform. Polym., 18, p.115 (2006).

12. Park, C. H.; Lee, C. H.; Guiver, M. D. \& Lee, Y. M. - Prog. Polym. Sci., 36, p.1443 (2011). http://dx.doi.org/10.1016/j. progpolymsci.2011.06.001

13. Hande, V. R.; Rath, S. K.; Rao, S. \& Patri, M. - J. Memb. Scie., 372, p.40 (2011). http://dx.doi.org/10.1016/j. memsci.2011.01.042

14. Jaafar, J.; Ismaila, A. F.; Matsuuraa, T. \& Nagaic, K. - J. Memb. Sci., 382, p.202 (2011). http://dx.doi.org/10.1016/j. memsci.2011.08.016 
15. Tartaglione, G.; Tabuani, D. \& Camino, G. - Microporous Mesoporous Mater, 107, p.161 (2008). http://dx.doi. org/10.1016/j.micromeso.2007.04.020

16. Gomes, A. C. O.; Tamashiro, A.; Uieda, B.; Pessan, L. A. \& Paranhos, C. M. - "Caracterização de membranas de poli(éter imida) para uso em células a combustível”, in: Anais do XIX Congresso de Iniciação Científica da Ufscar, v.7 (2011).

17. Silva, D. E. S. L. - "Desenvolvimento de membranas de poli(éter imida) sulfonada para a permeação de cátions", Dissertação de Mestrado, Universidade do Estado do Rio de Janeiro, Brasil (2006).
18. Goodwin, A. A. - J. Appl. Polym. Sci., 72, p.543 (1999). http://dx.doi.org/10.1002/(SICI) 10974628(19990425)72:4<543::AID-APP11>3.0.CO;2-B

19. Shen, L-K.; Xu, Z-K.; Yang, Q.; Sun, H. L.; Wang, S-Y. \& Xu, Y-Y. - J. Appl. Polym. Sci., 92, p.1709 (2004). http:// dx.doi.org/10.1002/app.20128

20. Paranhos, C. M.; Soares, B. G.; Oliveira, R. N. \& Pessan, L. A. - Macromol. Mater. Eng., 292, p.620 (2007). http:// dx.doi.org/10.1002/mame.200700004

Enviado: Abr. 19, 2012

Reenviado: Fev. 17, 2014 Aceito: Mar. 5, 2014 